\title{
Experimental and Numerical Analysis of the Seismic Behavior of Outer Shell Joints for H-Shaped Steel Beam and Square Tubular Column
}

\author{
Dan Zhang ${ }^{1}$, Zhong Tao ${ }^{1, \%}$ and Lei Zhang ${ }^{2}$ \\ ${ }^{I}$ Faculty of Civil Engineering and Mechanics, Kunming University of Science and Technology, Kunming 650500, China \\ ${ }^{2}$ School of Natural and Built Environment, Queen's University Belfast, Belfast, BT7 INN, United Kingdom
}

Received 27 November 2016; Accepted 25 April 2017

\begin{abstract}
A considerable amount of welding has a negative effect on traditional joints. Experimental and numerical studies of new bolted outer shell joints under low reversed cyclic loading were presented, and a total of four outer shell joints of Hshaped steel beam and square tubular column were tested with experimental parameters, such as sectional dimensions and concrete in the tubular column, to improve the beam-to-column joint form. Moreover, the cooperative deformation behavior between the outer shell and the column wall was discussed. In addition, complementary finite element simulation was used, and its results were compared with the experimental results. On this basis, the main indexes that affected the performance of the joints were analyzed. Results show that the hysteresis curves of the outer shell joints are full, the bearing capacity and initial stiffness are significantly improved with the increase in the sectional dimensions, while the ultimate rotation angles are reduced, degrading the stiffness to 0.13-0.24 times its initial stiffness at the last loading level. Notably, the strain ratios of the outer shell and the adjacent steel tubular column are approximately 1:2.5 in the elastic stage. Parametric analysis shows that the thickness of the outer shell should be approximately $8 \mathrm{~mm}$. Similarly, the $11 \mathrm{~mm}$ thick T-steel web with regard to the setting stiffener is significant in improving bearing capacity. The proposed study provides a theoretical reference for the application of outer shell joints in practical engineering.
\end{abstract}

Keywords: Beam-column joint, Outer shell, Quasi-static test, Seismic performance, Finite element analysis

\section{Introduction}

The beam-column joint is an important part of steel frames because its safety and reliability are the prerequisites for ensuring the normal use of an entire building. The design of the beam-to-column joints should exhibit sufficient strength and proper stiffness. During a strong earthquake, the formation and development of the plastic zone can dissipate ground vibration energy. The square tube column has the advantages of equal bi-axial bending stiffness and thin wall thickness, which is adopted by many industrial buildings and high-rise steel structures. Therefore, a new type of $\mathrm{H}$-shaped beam and square steel tubular column joint with reasonable force, simple structure, and convenient processing is critical to ensure the good mechanical performance of steel structures under possible earthquake.

Compared with the traditional H-shaped steel beamcolumn joints, square steel tubular column-H-shaped steel beam joints have more joint forms. Local and foreign studies mainly focus on the inner diaphragm joints, diaphragmthrough joints, and external stiffening ring joints. These commonly used joints have large stiffness, high bearing capacity, and a certain degree of ductility and toughness.

However, due to the complicated construction of the joints, as well as the influence on the bearing capacity of

*E-mail address: tsykmust@126.com

ISSN: 1791-2377 @ 2017 Eastern Macedonia and Thrace Institute of Technology. All rights reserved. steel column, the application and extension of square steel tubular column-H-shaped steel beam joints are limited. For example, with regard to internal welding in the inner diaphragm joint [1-2], the difficulty of welding is increased, and the existence of the diaphragm will affect the concrete filling. The diaphragm-through joint is improved based on the former [3], however, the actual seismic performance is poor, and most of the failure modes are weld cracking. Although the external stiffening ring joint [4] has a good load transfer path, the amount of welding will significantly rise when the number of projects increases, thereby directly affecting the schedule and project cost. Moreover, the external stiffening ring joint is inconvenient for the building layout because of the large joint size.

Improving the existing joints of square steel tubular column and $\mathrm{H}$-shaped steel beam is necessary to eliminate the drawbacks of the previously mentioned joints. Considering the adverse effects of field welding on the fabrication of joints, a full-bolted outer shell beam-column joint was proposed, and its mechanical properties were studied.

\section{State of the art}

Numerous forms of steel frame beam-column joints exist because of their different characteristics. Many studies on the failure modes, bearing capacity, and initial stiffness of steel tubular joints through experimental and finite element 
methods have been conducted by domestic and foreign scholars, and a few calculation methods have been provided for engineering design. However, the study object was mainly traditional welded steel tubular joints. Wang et al. [5] conducted a monotonic loading experiment to study the behavior of extended end-plate joints of circular or square concrete-filled steel tubular (CFST) columns. Results showed that joints exhibited high strength and stiffness, while its rotation ability satisfied the demand of seismic ductility. Chen et al. [6] investigated the performance of eight different parameter joints of a square hollow section brace-H-shaped steel chord under axial compression and discussed the angle of the stiffening ribs. The local buckling failure of the brace member was the main failure mode during the tests. Dessouki et al. [7] performed a monotonic loading test on five connections of steel I-beams to square CFST columns, and the effect of column stiffening dimensions and filling the column with concrete on the ultimate bending moment of joints was analyzed. Deylami et al. [8] completed the low-cycle reciprocating loading test of the connection between I-beam and a built-up box column, investigated the effect of the geometry and position of the vertical rib plate on seismic behavior, and performed finite element analyses to confirm that the reinforcement of the vertical rib plate can significantly enhance the performance of the joint. In the preceding studies, the connection form of the beam-column joint is mainly welding. In addition, the plastic hinge failure mode will appear under the strict guarantee of the weld quality, and the plastic hinge must be located away from the joint region; otherwise, it will adversely affect the seismic performance of joints.

Liu et al. [9] examined the mechanical behavior of open beam-to-tubular column bolted connections with angles to avoid stress concentration in welds. Yang et al. [10] presented seven experimental performance tests of bolted steel beam-column joints under a central-column-removal scenario. The test results indicated that the mechanical properties of the web cleat connection were the best. As seen from the preceding studies, avoiding the defects in the welds by using the bolted connection is effective. However, the energy of the joint area is dissipated by the deformation of the connecting parts. Moreover, a sign of brittle failure of the joints exists in the test, and the deformation of the column wall is large in the absence of effective reinforcement. These are the reasons the beam end does not form a plastic hinge as expected, thereby failing to meet the design principle of strong nodes and weak components.

When analyzing the seismic behavior of the joints, the influence of loading mode on the mechanical properties of the joints cannot be ignored. Wang et al. [11] conducted an experimental program to evaluate the low cycle fatigue behavior of bolted connections to hollow structural section columns and obtained the most influential geometric details of the connection. Rong et al. [12] investigated the mechanical properties and failure modes of diaphragmthrough joints of CFST columns and found that the tensile load of the steel beam flange was shared by the square steel tube and the diaphragm. Four specimens were tested under static tension loads to further study the bending capacity of the panel zone of diaphragm-through joint [13]. The boundary condition of low-cycle reciprocating loading in the experiment is closer to the stress state of the joints in the actual structure, and the mechanical performance of the joints can be realized under the action of the earthquake. However, the loading patterns of the preceding studies are monotonic loading or static tensile loading, and these loading modes may affect the accuracy of the test results.

In addition to the experimental study, finite element analysis (FEA) has become one of the important research methods, and the results have also been recognized by the engineering and academia. Han et al. [14] studied eight cast steel joints of the H-shaped beam and square tube column through static monotonic loading test. On the basis of the deformation compatibility condition, the bearing capacity theory can be validated by FEA. Yang et al. [15] performed FEA on the beam to concrete-filled elliptical steel tubular column joints and analyzed the key parameters that affect the performance of joints. Augusto et al. [16] used the finite element method to simulate the web components in endplate beam-to-column joints under cyclic loading, establishing the foundation for the analysis of the energy dissipation of steel joints. The preceding studies have established a refined model, however, the joint model has been simplified to varying degrees, such as scaling the joint size or ignoring the contact definition between the components, to improve the computational efficiency. These treatments will affect the mechanical properties of the joints.

Therefore, in view of the shortcomings of the existing studies, this study presents a new type of full-bolted beamto-column outer shell joint, that is, the square steel tubular column with outer shell in the joint region is thickened, the core area stiffness of the joint is enhanced, and the beam and the column are connected by the T-shaped steel and high strength bolts. On this basis, the low-cycle repeated loading test of four outer shell joints selected from the actual engineering was performed to study the failure characteristics and seismic performance. In addition, the synergistic deformation performance of the outer shell and the column wall was verified. ABAQUS finite element software was used for the numerical simulation of full-scale outer shell joints. The key parameters that affect the mechanical properties of the joints were also studied, which provided the theoretical basis for the application of the new joints.

The rest of the study is organized as follows. Section 3 describes the quasi-static test and finite element modeling method. Section 4 analyzes the failure modes, bearing capacity, and hysteretic performance of the outer shell joints, gives the influences of the beam-column section dimension and filling concrete in the column on the mechanical properties, verifies the finite element model, and presents the parameters that influence the bearing capacity of the joints. Section 5 summarizes this study and provides relevant conclusions.

\section{Methodology}

\subsection{Test program}

\subsubsection{Specimen design}

The deformation of the plane frame during a horizontal earthquake is shown in Fig. 1. To consider the position of the anti-bending points when the frame is subjected to horizontal load, the intermediate joint of the middle layer in the plane steel frame was selected to facilitate the study of the seismic performance of the beam-column connection joint under reciprocating load. The length of the symmetrical column of the upper and lower sides of the joint was approximately half the actual column height, and the length of the left and right sides of the beam was close to the half the actual beam span according to the laboratory and 
production conditions. The full-scale joint specimens were chosen to reflect the material properties and the characteristics of the steel structure residence and to ensure that the specimens meet the actual design.

Cruciform joints were selected, and a total of four specimens were produced. According to the different crosssectional dimensions, the specimens were divided into two groups: A and B. STj-A and STj-B were steel tubular joints, and CFSTj-A and CFSTj-B were concrete-filled steel tubular joints. The specimen parameters are shown in Fig. 2.

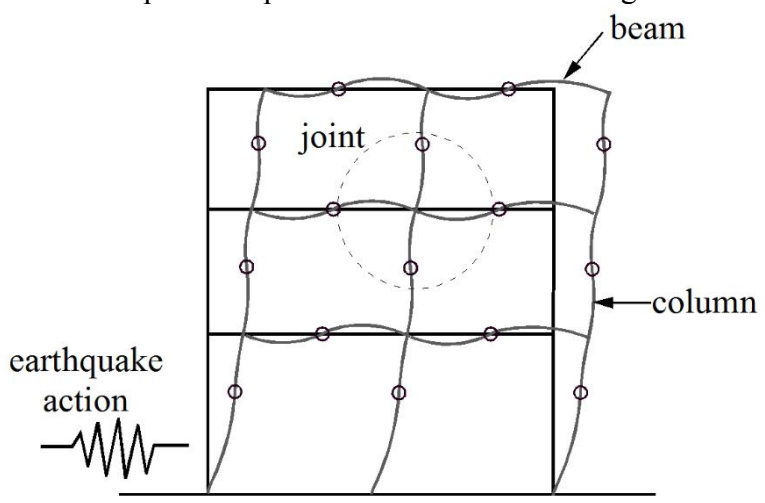

Fig. 1. Deformation of plane frame

The cross-section of the square steel tubular column in group A was $300 \mathrm{~mm} \times 8 \mathrm{~mm}$. The cross-section of the Hshaped steel beam in group A was HN $248 \mathrm{~mm} \times 124 \mathrm{~mm} \times$ $5 \mathrm{~mm} \times 8 \mathrm{~mm}$. The cross-sections of the column and the beam in group B were $350 \mathrm{~mm} \times 8 \mathrm{~mm}$ and $\mathrm{HN} 346 \mathrm{~mm} \times$ $174 \mathrm{~mm} \times 6 \mathrm{~mm} \times 9 \mathrm{~mm}$, respectively. The beam and the column were connected with T-shaped steel and full bolts. The T-type steel had stiffeners. Friction-type high-strength bolts with a grade of 10.9 were used. The T-type steel flange and the column wall were connected by four high-strength bolts, and the T-type steel web and the beam flange were connected by six high-strength bolts. An E50-type welding electrode was used between the upper and lower edges of the outer shell and the steel tube column, and the outer shells were welded to each other in a V shape.

\subsubsection{Material properties}

The average yield strength $f_{y}$, ultimate tensile strength $f_{u}$, elastic modulus $E$, and Poisson's ratio $\mu$ are shown in Table 1. The failure of the tensile samples is shown in Fig. 3.

Table 1. Mechanical properties of steel

\begin{tabular}{l|l|l|l|l}
\hline Material & $\begin{array}{l}\text { Yield strength } \\
f_{y}\left(\mathrm{~N} / \mathrm{mm}^{2}\right)\end{array}$ & $\begin{array}{l}\text { Ultimate strength } \\
f_{y}\left(\mathrm{~N} / \mathrm{mm}^{2}\right)\end{array}$ & $\begin{array}{l}\text { Elastic modulus } \\
E\left(\mathrm{~N} / \mathrm{mm}^{2}\right)\end{array}$ & $\begin{array}{l}\text { Poisson ratio } \\
\mu\end{array}$ \\
\hline Beam flange & 424.7 & 560.9 & $2.03 \times 10^{5}$ & 0.29 \\
Beam web & 309.5 & 516.5 & $2.13 \times 10^{5}$ & 0.28 \\
Square steel tube & 421.1 & 546.0 & $2.02 \times 10^{5}$ & 0.28 \\
Outer shell & 417.3 & 554.6 & $2.02 \times 10^{5}$ & 0.28 \\
T-steel web & 350.1 & 489.2 & $1.94 \times 10^{5}$ & 0.27 \\
T-steel flange & 396.8 & 548.3 & $2.06 \times 10^{5}$ & 0.29 \\
\hline
\end{tabular}

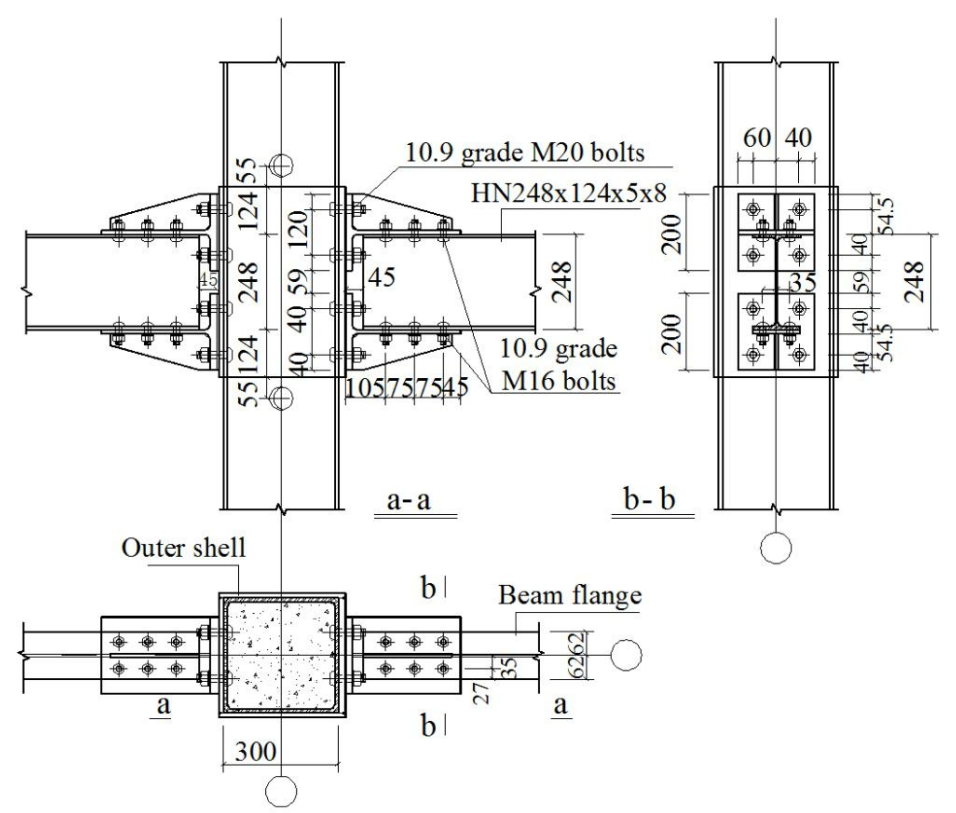

(a) 


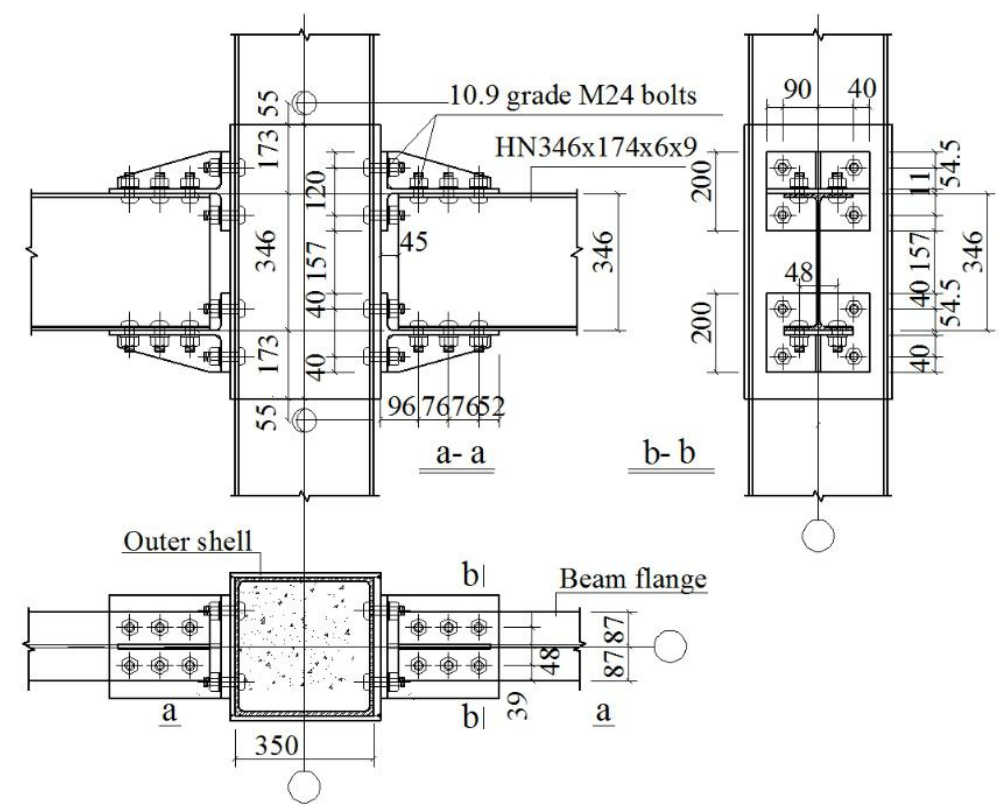

(b)

Fig. 2. Details of the outer shell joints. (a) Dimensions of group A. (b) Dimensions of group B result for the karate network.

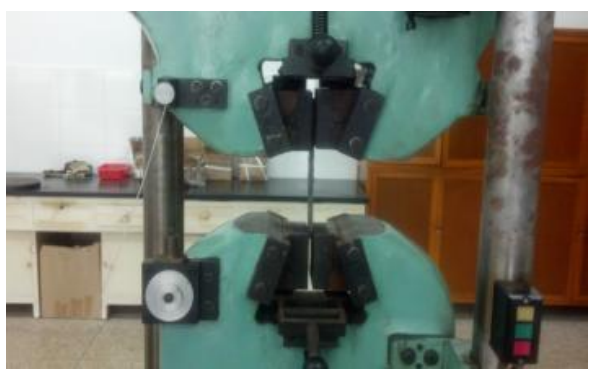

(a)

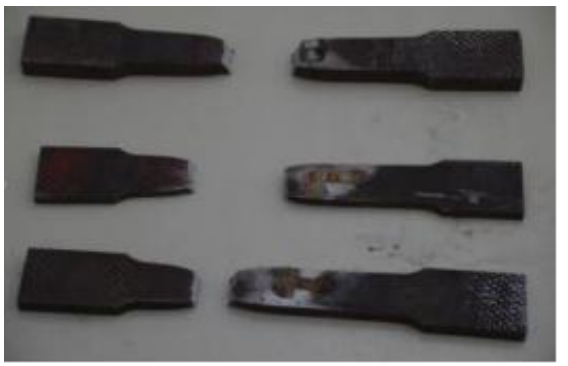

(b)

Fig. 3. Tensile test procedure. (a) Tensile test. (b) Sample failure result for the karate network.

The specimens were manufactured in the factory. Three samples of each group were retained according to the requirements of the standard material test, and the tensile test was conducted based on the tensile testing method of metal materials at room temperature. Hot-rolled H-shaped steel was chosen as the material, the nominal yielding strength of the steel was $345 \mathrm{~N} / \mathrm{mm}^{2}$, and the sampling location should avoid the weld and stress concentration area. All the samples were simultaneously processed along with the specimens, and the surface was treated with rust remover.

\subsubsection{Test setup and loading program}

As shown in Fig. 4, the beam-end loading mode was adopted for outer shell joints. In the field loading, the beam-tocolumn joint specimen was installed in the counter-force frame, it was fixed by horizontal pull rods to prevent out-ofplane instability, and spherical hinges were installed on the upper and lower ends of the column. The horizontal tension rods were contacted with the specimen by a roller device, thereby ensuring the free rotation of the joint in the plane. The column top was subjected to constant vertical pressure by a $2000 \mathrm{kN}$ hydraulic jack, and the axial compression ratio was 0.3. Anti-symmetric low-cycle reversed loads were applied on the free beam ends with vertical electro-hydraulic servo actuator (maximum load capacity is $1000 \mathrm{kN}$ ). The outer shell joints should be preloaded to eliminate the initial defects in the device and ensure that the equipment and instrument can work normally.
The test was performed based on the pseudo-static loading method. The mixed loading mode of the control force and control displacement was used. The specimen was subjected to graded loading controlled by force before yielding. After the specimen was yielded, the displacement control loading mode was adopted, the yield displacement $\Delta_{y}$ was obtained as displacement increment, and each loading level was repeated three times until the specimen was damaged. The reciprocating loading system is shown in Fig. 5.

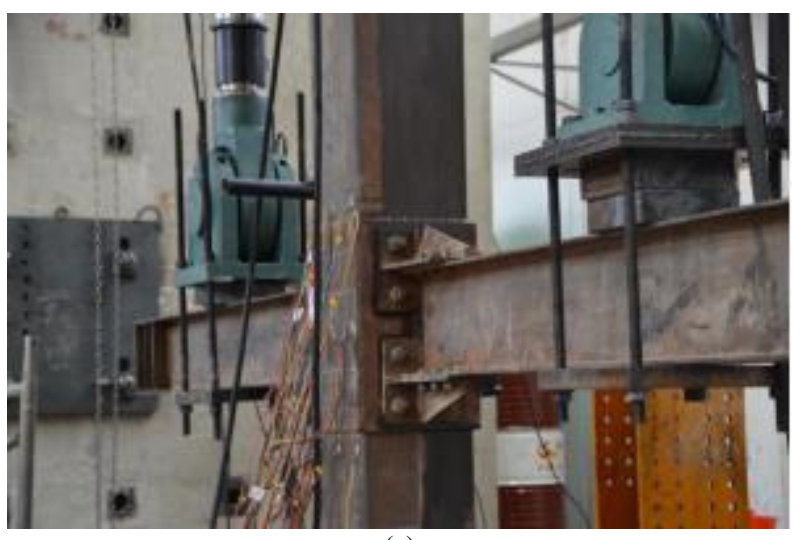

(a) 


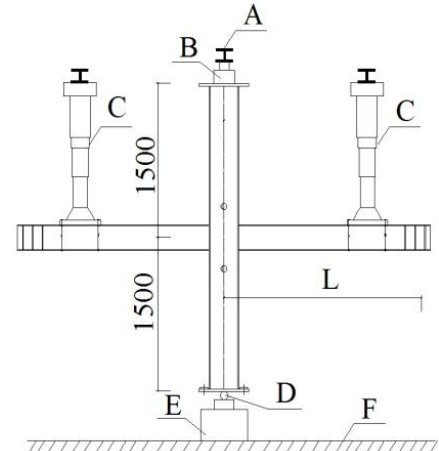

A-Reaction frame

B -Hydraulic jack

C -Reciprocating actuator

D -Spherical hinge bearing

E -Block

F -Test platform

Fig. 4. Test setup. (a) Photograph of test setup. (b) Schematic diagram of test setup

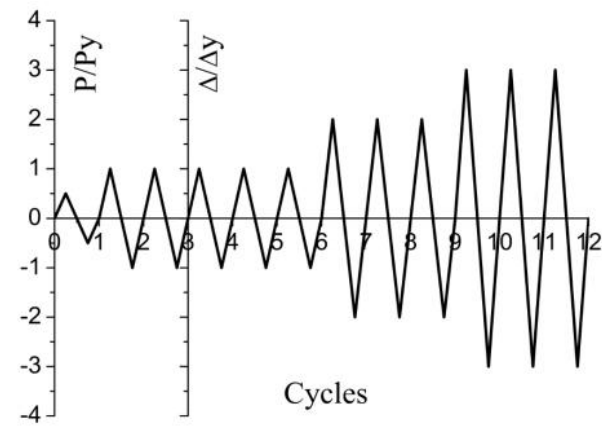

Fig. 5. Reciprocating loading system

\subsubsection{Measurement plan}

Deformation measuring instruments and strain gauges were the main test equipment. The displacement gauges were used to measure the deformation of the specimen, and the strain of the steel tube column, steel beam, and other components was measured by the resistance strain gauges to obtain the load-deformation law of the joint specimen. The test data of the displacement and strain gauges were collected by a static strain measurement system. In addition, the load and displacement values of the output of the liquid servo actuator were collected by a computer. According to the purpose of the test, the test contents were as follows:

(1) Axial pressure on the top of the column;

(2) Load and displacement values of the loading point on the beam end;

(3) Beam-column angle;

(4) Strain distribution in the core region of the joint.

The strain distribution of the components near the core area of the joint was collected by the DH3816 static strain acquisition system, and the layout of the strain gauges is shown in Fig. 6. The performance of the joint can be evaluated by analyzing these measured data.

\subsection{Finite element analysis}

A three-dimensional nonlinear FEA model of the outer shell joint of H-steel beam and square steel tubular column was established by using ABAQUS. The non-linearity of the material and geometry and the nonlinear contact between bolts and plates, steel and concrete were considered. The element selection, boundary condition, and meshing solutions were provided, and the reliability of the finite element model was verified through a comparison with the experimental results.

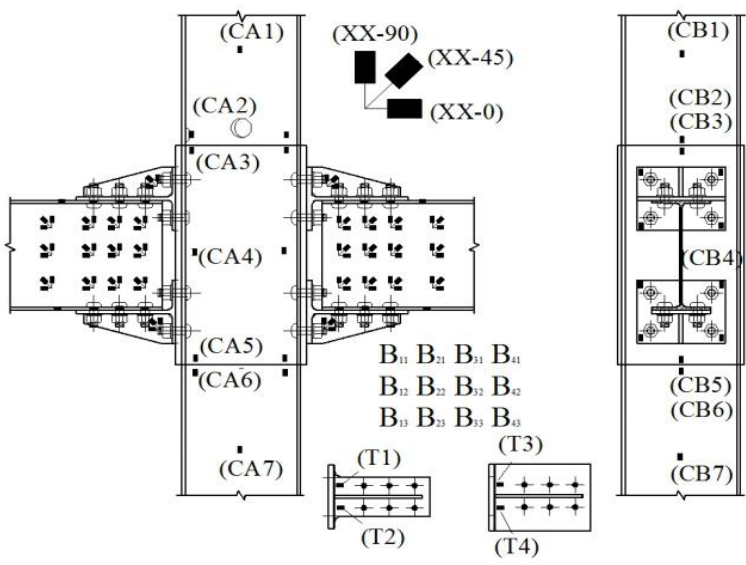

Fig. 6. Layout of strain gauges

\subsubsection{Material properties}

In the process of FEA, the stress-strain relationships of the square steel tubular column, H-steel beam, T-shaped steel, and other components were established according to the material test results, and the bilinear models were established. The stress-strain curve of the high strength bolt was simplified into an elastic-stiffened bilinear model. Moreover, the constitutive model of concrete considering the constraint of the steel tube was used to simulate the stressstrain relationship of core concrete [17].

\subsubsection{Element type and mesh generation}

When simulating the outer shell joint, the element type of each component of the joint, including the square steel tubular column, H-shaped steel beam, outer shell, T-shaped steel, and stiffening rib, needed to be specified to obtain a more detailed stress analysis of the joint, as well as provide a better simulation of the contact between different components and reduce the influence of the size effect. The joint model was modeled by using three-dimensional 8-node linear brick elements (C3D8R). The ABAQUS/Standard algorithm, which not only reduces calculation cost but also guarantees accuracy, was used.

Structured adaptive mesh generation was used to divide the mesh, then the regular hexahedral elements can be obtained this way. Owing to the complexity of the joint core area, focusing on the subdivision of this part is necessary. However, the division of the mesh away from the joint area can be relatively sparse.

\subsubsection{Contact and boundary conditions}

In accordance with different contact types, various contact pairs of the outer shell joint were defined. A contact pressure model in the normal direction and a coulomb friction model in the tangential directions were adopted to the surfaces between the $\mathrm{H}$-shaped beam flange and the $\mathrm{T}$-shaped steel web, the outer shell and the T-shaped steel flange, and the nut and the T-shaped steel. A tangential friction coefficient of 0.5 was used in the analysis. The contact between the screw and the bolt hole was defined as hard contact. Welding relationships between the components, such as outer shell to column wall and stiffening rib to T-shaped steel, were imitated by tie contact.

The reference points were established at the loading points of the free beam ends to reflect the boundary conditions of the joints, and the reference points were coupled with the beam loading surface to add the load directly to the reference points. The displacement constraints of $\mathrm{x}, \mathrm{y}, \mathrm{z}$ directions, as well as the rotational constraints of $\mathrm{x}$, 
$\mathrm{z}$ directions, were imposed to the column bottom, that is, the square steel tube column can be rotated in the xoz plane only. The displacement constraints of $\mathrm{x}, \mathrm{y}$ directions were applied to the column top. Then, the specimen can produce a vertical displacement in the z-direction. Equal and adverse low-cycle reciprocating displacement loads were added to the free beam ends in the vertical direction, respectively, as shown in Fig. 7. In addition, the y-direction constraint was simultaneously applied to prevent the torsion of the $\mathrm{H}$ shaped beam during the loading process.

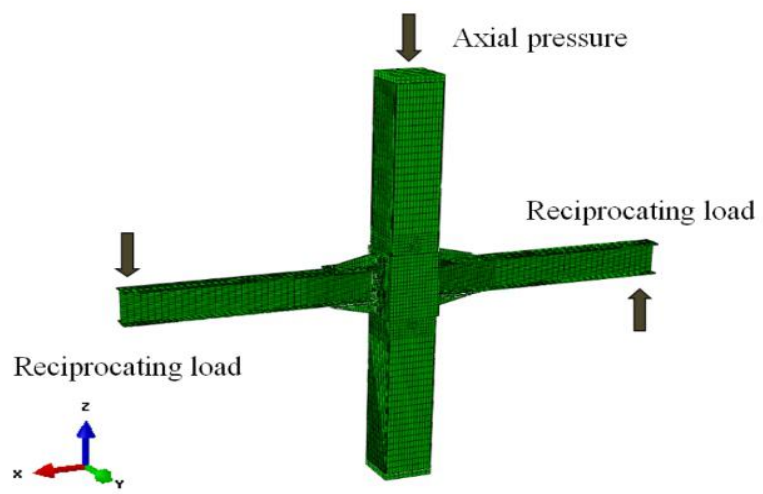

Fig. 7. Loading mode of the finite element model

\section{Result Analysis and Discussion}

\subsection{Test process and failure mode}

\subsubsection{Group A specimens}

In the load control stage, the specimens had no obvious deformation and were in the elastic range. The loaddisplacement hysteresis curves were basically linear at the beginning. When the displacement load was $22 \mathrm{~mm}$, the slope of the moment-rotation curve of the beam-end was changed, and the experimental curves showed that the initial stiffness of specimen CFSTj-A was significantly higher than that of specimen STj-A.

The friction caused by the application of the pre-tension of the high-strength bolts between the T-steel web and the $\mathrm{H}$-steel beam was overcome under the reciprocating load. Then, the outermost bolts of the lower flange of the H-steel beam were loosened. The plastic deformation of the beam end gradually accumulated. When the specimen STj-A was loaded to the level of $90 \mathrm{~mm}$, the weld between the outer shell and the column wall was cracked, as shown in Fig. 8(a) The beam flange buckled to a relatively mild degree, as shown in Fig. 8(b). Owing to the eccentricity of the actuator during the loading process, the $\mathrm{H}$-steel beam had a slight twist, the bolts had a significant slip, the nuts were deeply indented in the beam flange, and an obvious squeeze appeared between the bolts and the holes, as shown in Fig. 9(a). At the end of loading, an apparent concave and convex phenomenon was present on the beam web, and the H-steel beam was damaged by the combination of bending and torsion, as shown in Fig. 9(b).

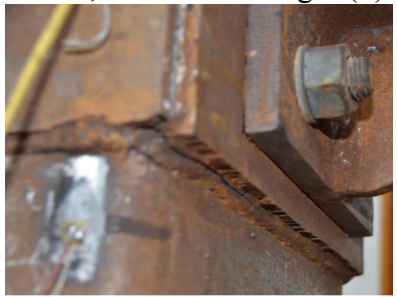

(a)

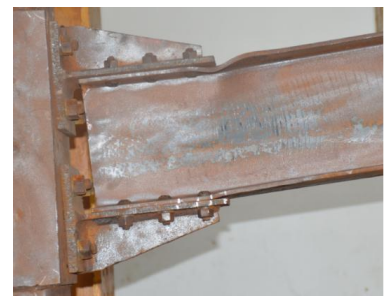

(b)
Fig. 8. Damage of the STj-A specimen. (a) Weld cracking. (b) Slight buckling

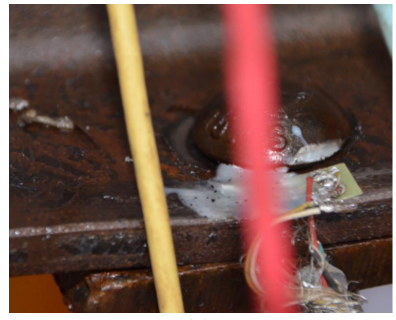

(a)

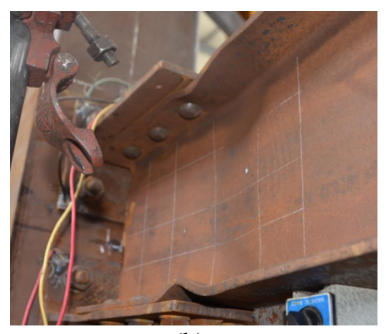

(b)
Fig. 9. Damage of the CFSTj-A specimen. (a) Bolt hole extrusion. (b) Buckling damage

\subsubsection{Group B specimens}

The cross-sectional dimensions of the beam-column joints of group B were larger than those of group A. In the initial stage of loading, the joint specimen was in the elastic range, which can be confirmed by the load-displacement hysteresis curve. No obvious deformation existed in the core area of the joint. The load was rapidly growing in this stage, and the initial stiffness was significantly higher than that of the group A specimens. Similarly, the stiffness of the CFSTj-B specimen was larger than that of the STj-B specimen.

At a loading level of $28 \mathrm{~mm}$, the slope of the test curve was obviously changed, lagging behind the yield loading level of group A. At a loading level of $44 \mathrm{~mm}$, a crack at the root of the lower T-steel was observed for the STj-B specimen, as shown in Fig. 10(a). Then, the crack almost penetrated the entire T-shaped flange, and the T-shaped steel of the CFSTj-B specimen eventually broke into two parts from the root of the web, exhibiting the typical shear brittle damage as determined by the fracture morphology shown in Fig. 10(b). At the end of the test load, the high-strength bolts on the beam flange did not show signs of significant sliding.

Considering the different sectional dimensions of the two group specimens, the damage forms were relatively different. Filling concrete in the column did not have much effect on failure modes. However, filling concrete had a considerable influence on the bearing capacity and initial stiffness of the outer shell joints.

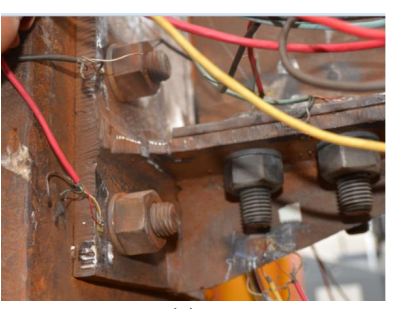

(a)

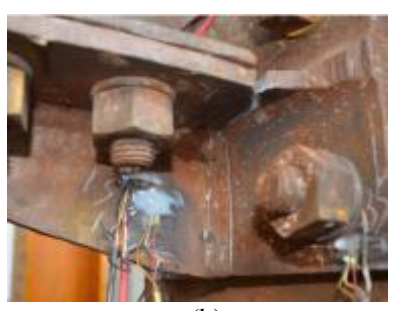

(b)
Fig. 10. Damage of group B specimens. (a) Fracture of lower T-steel web. (b) Crack extension

\subsubsection{Failure mode}

From the experimental phenomena, two kinds of failure modes of the outer shell joints were observed: (1) buckling failure of beam flange, and the plastic hinge was far away from the node area, such as in the group A specimens, (2) fracture of T-steel web root, such as in the group B specimens.

The damage mode of group A specimens was the buckling of the beam flange at the end of the T-steel web. The position of the plastic hinge can better protect the core area. The ultimate bending capacity was greater than the plastic bending capacity, thereby meeting the seismic design requirement of strong joint and weak components. Before the plastic buckling of the beam flange, the components of joint region failed to reach the ultimate bearing capacity, 
therefore, the joint core area was relatively safe, which was an ideal failure mode. However, the STj-A specimen lack restriction of concrete in the column, and the welding seam was in the range of local tensile plastic deformation of the column flange, hence, the stress of the weld was large. For the group B specimens, the root of the T-steel web was the weak spot, and the actual carrying capacity of the T-steel web was less than the strength design value. Then, the tension-shear failure of the T-steel web occurred.

\subsection{Moment-rotation hysteresis curve}

The hysteresis curve is a comprehensive indication of the seismic performance of the joint, which refers to the loaddeformation relationship of the joint under repeated load. This curve can show the characteristics of the strength, stiffness degradation, energy dissipation, and ductility, thereby indicating that more energy dissipated by joints corresponds to superior seismic performance. The loaddisplacement curves of the free beam-ends were obtained from the experiment. The displacement of the beam-end comprised the deformation of the $\mathrm{H}$-steel beam itself, the square steel tube column, and the core region of the joint. Therefore, the moment-rotation hysteresis curves can reflect the mechanical properties of the entire joint.

The moment-rotation hysteresis curve of each test specimen is shown in Fig. 11. The failure modes of the specimens had the following characteristics:

(1) At the initial stage of loading, the hysteresis curves of the specimens were nearly linear, and hysteresis loops were not formed. Moreover, the stiffness of the joints was basically the same, the joints were in the elastic range, and the plastic deformation on the local part of the component can be ignored.

(2) With the increase in the load, the slope of the curve decreased with the increase in the number of loading and unloading times, which indicated that the stiffness of the specimen was gradually degraded. This condition was mainly related to the deformation of the joint region and the beam end. The unloading stiffness was close to the initial stiffness of the joint, and the degradation rate of the unloading stiffness was not as obvious as that of the loading stiffness. The residual deformation of the joint gradually increased when unloading, thereby indicating that the specimen had entered the elastic-plastic stage.

(3) In the early stage of loading, the hysteresis curves of the specimens in group A were spindle-shaped. After repeated reciprocating load, arched curves and a certain degree of pinch appeared. The pinching degree was gradually increased, which was related to the slip of the high-strength bolts of the beam flange and was consistent with the phenomenon in the test. After the specimen entered the elastic-plastic stage, the hysteresis curves of positive and negative loading were incompletely symmetrical, especially the bearing capacity.

(4) The hysteresis curves of the two specimens in group B were similar to the spindle-shaped curves, the hysteresis loops were narrow, and the energy dissipation capacity was weak. This result can be attributed to the two broken specimens by the root of the T-steel web, thereby leading to the incomplete development of hysteresis loops of these specimens. The energy dissipation performance of group B was poor, thereby indicating that the T-shaped steel and the stiffening ribs should be strengthened in the seismic design.

Compared with the CFSTj specimens, the hysteresis loop area of the $\mathrm{STj}$ specimens was fuller and the energy dissipation capacity was stronger. The hysteresis curves of group A were plumper than those of group B joints. In general, the seismic performance of outer shell joints was good.

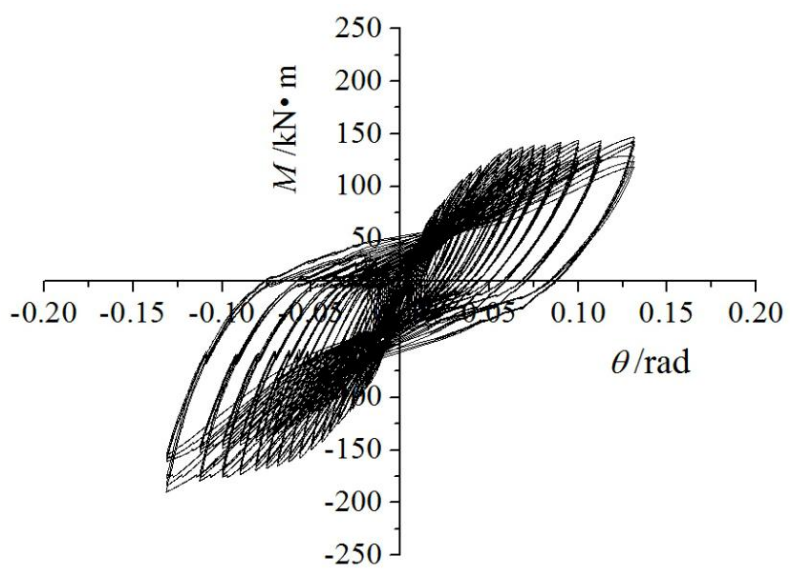

(b) 


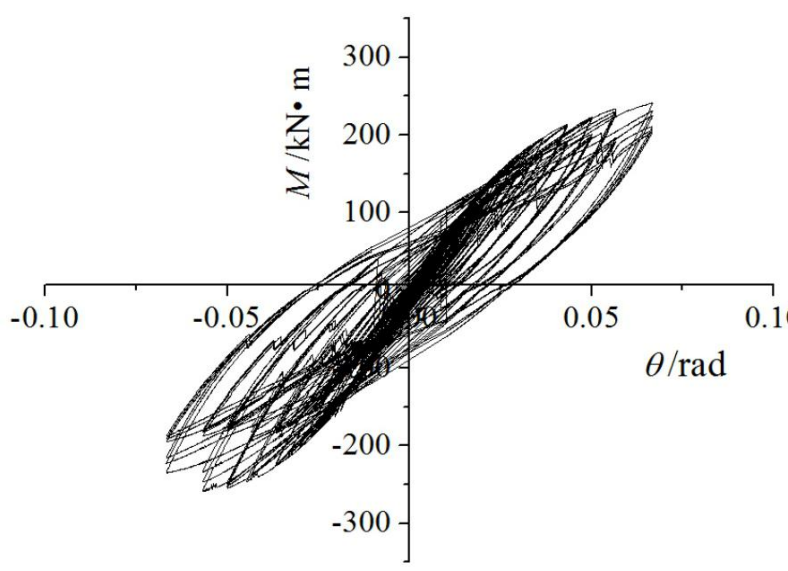

(c)

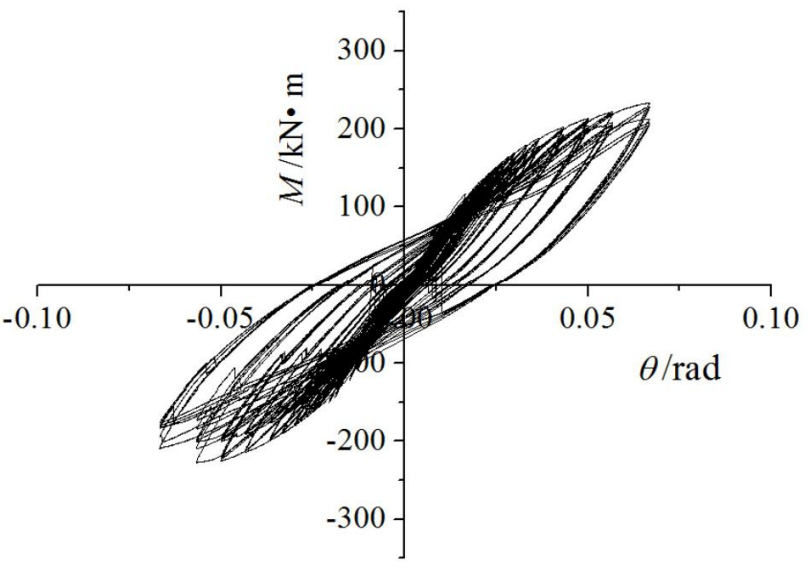

(d)

Fig. 11. Moment-rotation hysteresis curves. (a) STj-A. (b) CFSTj-A. (c) STj-B. (d) CFSTj-B of the outer shell joints.

\subsection{Moment-rotation skeleton curve}

According to the results of the hysteresis curves of the experiment, the maximum points of the positive and negative directions were respectively connected. Then, the skeleton curves of the joint specimens were obtained. The skeleton curves of the specimens are shown in Fig. 12. Overall, the skeleton curves were approximately S-shaped. Under cyclic loading, the specimen underwent three stages of elasticity, yield, and plasticity until the ultimate damage, the bearing capacity, initial stiffness, and the ultimate rotation, as shown in Table 2.

The experimental results showed the following: 1) The skeleton curves of group A joints were close to each other. After entering the displacement control stage, the bearing capacity did not significantly decrease along with the loading, thereby indicating that the ductility of the specimen was good. The trend of the skeleton curves of group B specimens was relatively consistent, the bearing capacity was high, the initial stiffness was large. The skeleton curves were not completely symmetrical, thereby indicating that the specimens had a few accumulated damages during the loading process. 2) The average bearing capacities of groups $\mathrm{A}$ and $\mathrm{B}$ were 159.32 and $235.76 \mathrm{kN} \cdot \mathrm{m}$, respectively, which illustrated that increasing the dimensions of the joint can effectively improve the bearing capacity. 3) The initial stiffnesses of the specimens of group A were 5025.27 and $6409.3 \mathrm{kN} \cdot \mathrm{m} \cdot \mathrm{rad}^{-1}$, respectively, and 12635.40 and $14082.72 \mathrm{kN} \cdot \mathrm{m} \cdot \mathrm{rad}^{-1}$ for group $\mathrm{B}$, respectively, thereby indicating that increasing the joint size can improve the initial stiffness. 4) The ultimate rotation angles of the specimens of group A were approximately twice that of group B. However, the filling concrete in the column had a small effect on the ultimate rotation angle.

Table 2. Mechanical properties of outer shell joints

\begin{tabular}{|c|c|c|c|c|c|c|}
\hline $\begin{array}{l}\text { Specimen } \\
\text { group }\end{array}$ & $\begin{array}{l}\text { Specimen } \\
\text { number }\end{array}$ & $\begin{array}{l}\text { Ultimate } \\
\text { moment } \\
\mathrm{M}_{u}(\mathrm{kN} \cdot \mathrm{m})\end{array}$ & $\begin{array}{l}\text { Plastic moment } \\
\mathrm{M}_{\mathrm{P}}(\mathrm{kN} \cdot \mathrm{m})\end{array}$ & $\mathrm{M}_{\mathrm{u}} / \mathrm{M}_{\mathrm{p}}$ & $\begin{array}{l}\text { Initial stiffness } \\
K_{0}\left(\mathrm{kN} \cdot \mathrm{m} \cdot \mathrm{rad}^{-1}\right)\end{array}$ & $\begin{array}{l}\text { Ultimate rotation angle } \\
\theta_{u}(\mathrm{rad})\end{array}$ \\
\hline \multirow{2}{*}{ Group A } & STj-A & 154.35 & \multirow{2}{*}{129.6} & 1.19 & 5025.27 & 0.131 \\
\hline & CFSTj-A & 164.28 & & 1.27 & 6409.30 & 0.128 \\
\hline \multirow{2}{*}{ Group B } & STj-B & 241.34 & \multirow{2}{*}{292.80} & 0.82 & 12635.40 & 0.066 \\
\hline & CFSTj-B & 230.18 & & 0.79 & 14082.72 & 0.062 \\
\hline
\end{tabular}

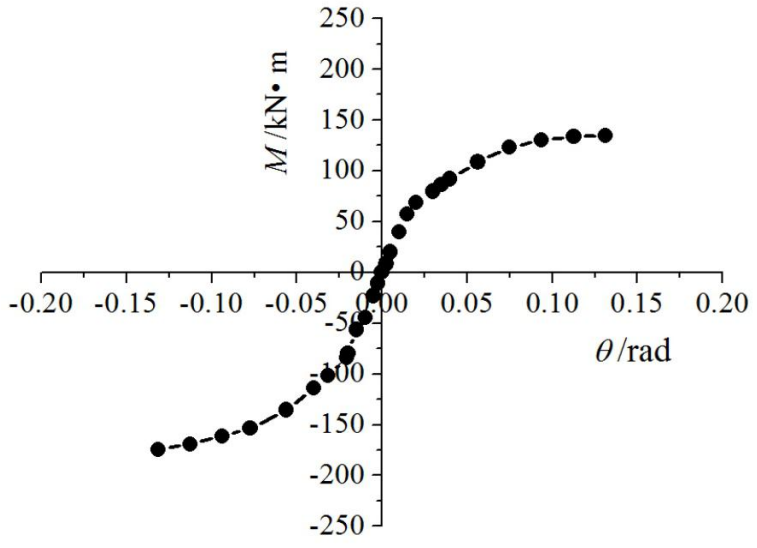

(a)

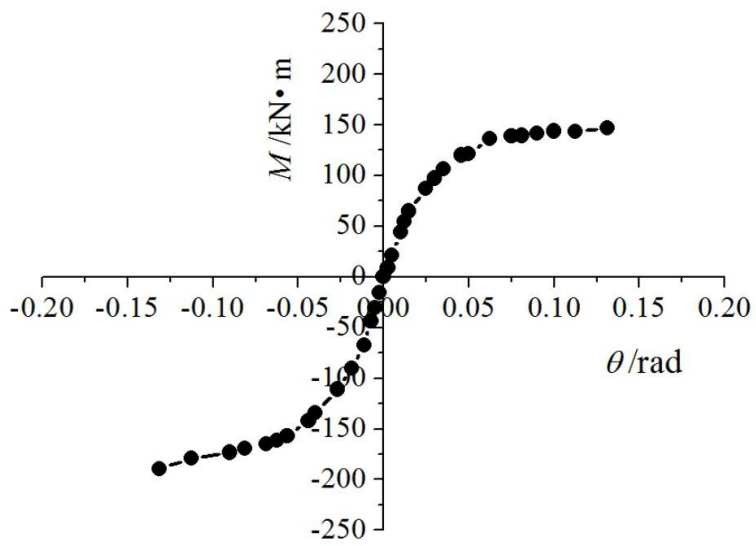

(b) 


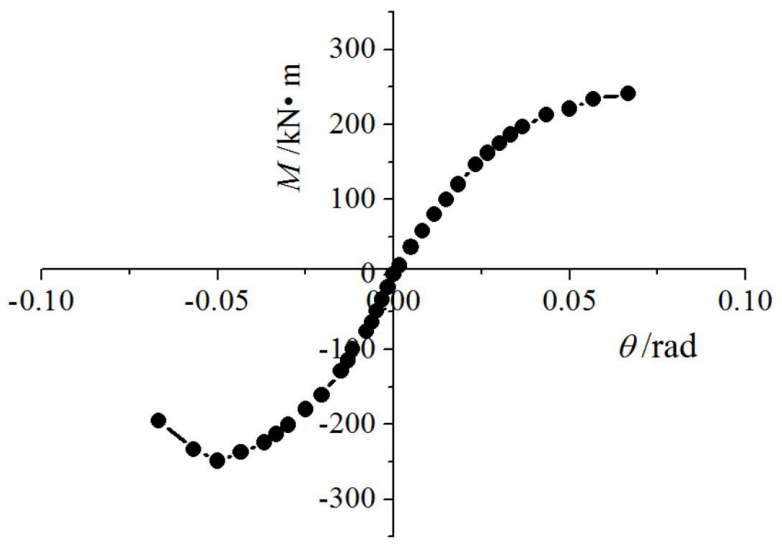

(c)

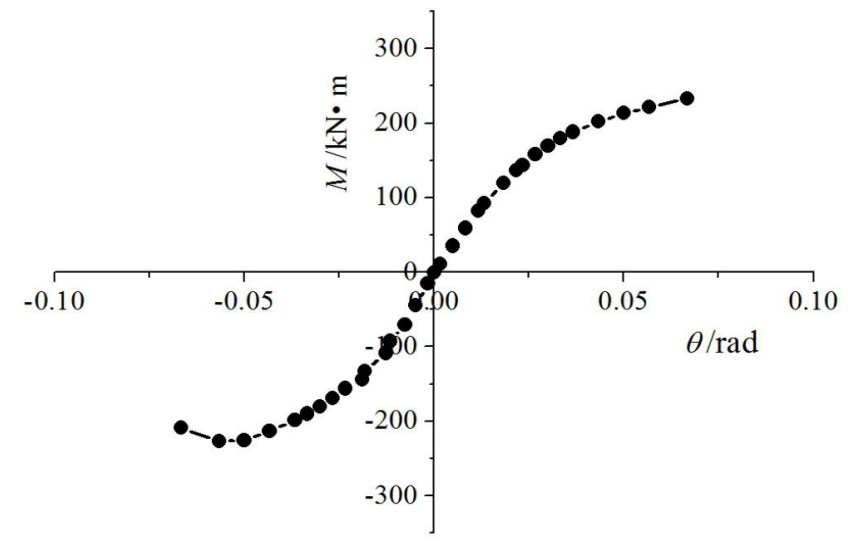

(d)

Fig. 12. Moment-rotation skeleton curves. (a) STj-A. (b) CFSTj-A. (c) STj-B. (d) CFSTj-B hysteresis curves.

\subsection{Stiffness degradation}

Compared the loading process in the same direction, the tangent slope of the next loading is lower than that of the last one, which illustrates that the stiffness of the beam and column members is reduced under cyclic loading. The stiffness degradation of the joint is defined as the stiffness that is reduced by the increase in the number of reciprocating loads.

The stiffness of the outer shell joints is described by the secant stiffness, the effective stiffness of the $i_{t h}$ loading level is defined by Equation 1, and the relationships between the $K_{i} / K_{0}$ and $\theta_{i} / \theta_{u}$ are shown in Fig. 13, where $K_{0}$ is the initial rotational stiffness of the joint, and $\theta_{u}$ is the ultimate rotation angle of the joint.

$\mathrm{K}_{\mathrm{i}}=\frac{\left|+\mathrm{M}_{\mathrm{i}}\right|+\left|-\mathrm{M}_{\mathrm{i}}\right|}{\left|+\theta_{\mathrm{i}}\right|+\left|-\theta_{\mathrm{i}}\right|}$

where $\mathrm{M}_{\mathrm{i}}$ is the peak bending moment of the joint under the $i_{\text {th }}$ loading level, and $\theta_{i}$ is the peak rotation angle for the joint that corresponds to the $i_{\text {th }}$ loading level.

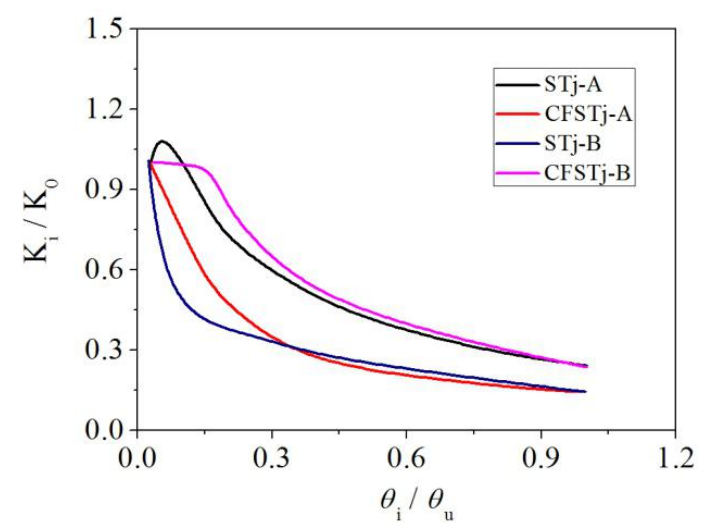

Fig. 13. Stiffness degradation curves

The stiffness degradation of the four specimens was fast at the initial stage of loading. Then, the degradation degree of each specimen gradually became gentle. In the last loading stage, the stiffness of four joints was reduced to its 0.13-0.24 times initial stiffness.

\subsection{Strain analysis}

The outer shell and the column flange were connected by fillet welds. Relative sliding between the two components may occur in the process of loading because the contact surface was not completely binding. Therefore, studying the cooperative working performance of outer shell and column wall is necessary.

The column wall and the outer shell were assumed to be in a fully cooperative working condition. The stress was basically equal in the same area, thus, the cross-sectional area of the column wall was inversely proportional to the stress value of the surface. The total thickness of the outer shell strengthened area on the column flange side (the sum thickness of the outer shell and the column wall) in groups A and B was 20 and $24 \mathrm{~mm}$, respectively, and the thickness of the adjacent column wall was $8 \mathrm{~mm}$. Therefore, the ratios of the surface strain between the outer shell and the column wall for groups A and B should be 1:2.5 and 1:3, respectively. The comparative strain analyses of $\mathrm{STj}-\mathrm{A}$, CFSTj-A, and STj-B specimens are shown in Fig. 14-16.

In the elastic stage, for $\mathrm{STj}-\mathrm{A}, \mathrm{CFSTj}-\mathrm{A}$, and $\mathrm{STj}-\mathrm{B}$ specimens, the ratios of the maximum compressive strain of the column wall to the adjacent outer shell were 2.73, 2.26, and 2.3 , respectively, and the ratios were 2.24, 1.56, and 1.53 , respectively, in the plastic stage.

For the two group specimens, the maximum compressive strain of the column wall was close to 2.5 times the strain values of the outer shell under the ideal working condition in the elastic stage. The ratio of STj-A specimen in group A can still be guaranteed to be approximately 2.5 in the plastic stage. However, the ratios of CFSTj-A and STj-B specimens in the plastic stage cannot satisfy the preceding relationship well, yet the change rules of the two components were coincident. The possible reason for the change of the strain ratios was that the distance between the measuring point and the fillet weld was too close. After the specimens entered the plastic stage, the deformation of the fillet weld was more likely to occur, which may have influenced the codeformation of the two components. The strain ratios can satisfy the preceding relations well in the elastic stage, thereby also confirming this conclusion. Hence, strict quality control of the welds between the outer shell and the column wall is an important guarantee for cooperative working.

The preceding analysis shows that when the deformation of the joint region is small, the cooperation performance of the outer shell and the column wall is close to the ideal working condition, and the cooperative work performance of the two components is weakened when the deformation of 
the joint region is large. Fig. 14-16 show that the change of the strain values that correspond to the outer shell and the adjacent column wall is different in each stage, however, the trend is consistent. This finding proves that the outer shell can be deformed together with the square steel tube column, which can effectively enhance the stiffness and bearing capacity of the column section of the joint region to strengthen the column.

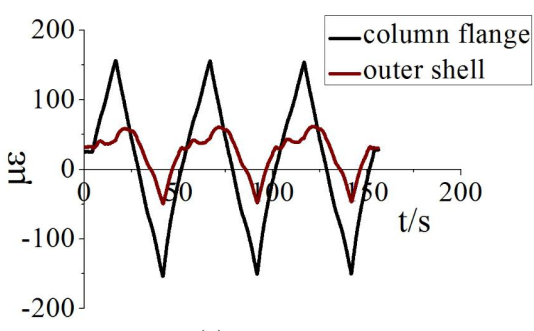

(a)

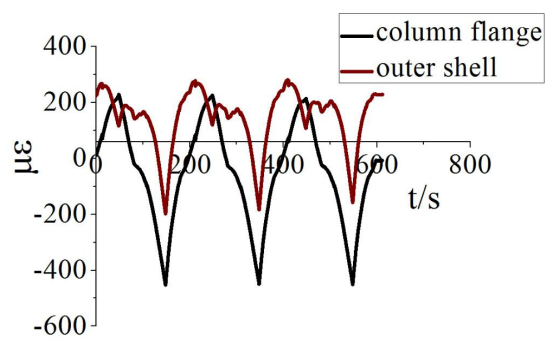

(b)

Fig. 14. Strain distribution of the STj-A. (a) Elastic stage. (b) Plastic stage

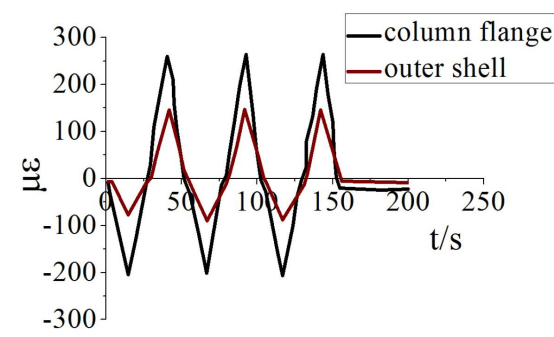

(a)

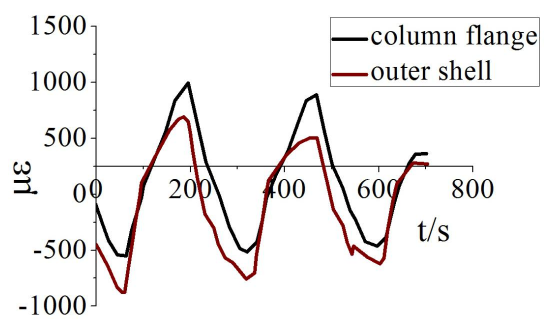

(b)

Fig. 15. Strain distribution of the CFSTj-A. (a) Elastic stage. (b) Plastic stage

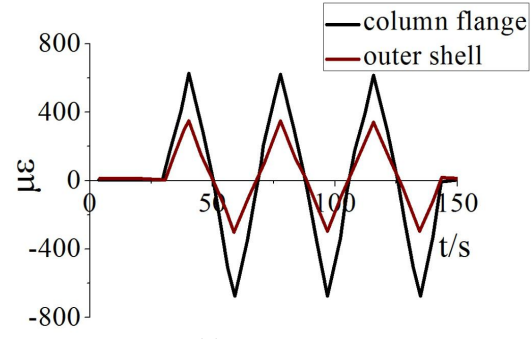

(a)

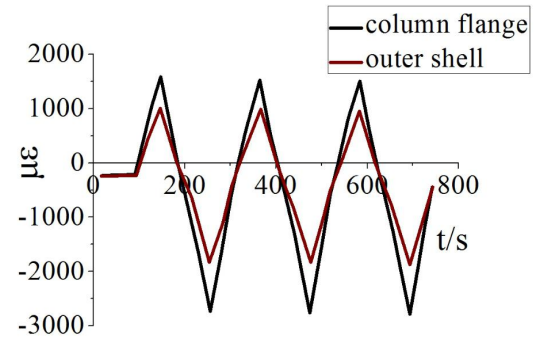

(b)

Fig. 16. Strain distribution of the STj-B. (a) Elastic stage. (b) Plastic stage

\subsection{Validation of finite element model}

Figure 17 shows a comparison of the skeleton curves between the FEA method and the test, and the comparison results are shown in Table 3.

(1) The skeleton curves of the FEA and the test were all S-shaped, thereby showing that the joint specimen underwent three stages of elasticity, yield, and plastic development during the loading process. In the early stage of loading, the change rule and growth trend of the finite element skeleton curves were in good agreement with the experimental skeleton curves. Owing to the idealization of the material properties in the FEA, the error of ultimate bending moment between the numerical simulation and the experiment was controlled within $10 \%$ in group A, while the skeleton curves of group B were basically coincident, which proved the rationality of the modeling method.

(2) The skeleton curves of the FEA were symmetrical. However, the symmetry of the positive and negative skeleton curves in the experiment was slightly worse. Although the lateral pull rod constraints were set to prevent the specimen from being twisted in the loading process, the residual deformation still existed, thereby resulting in the deviation of symmetry between the positive and negative skeleton curves. However, the numerical analysis did not consider this factor, and the symmetry was better.
(3) The skeleton curves of finite element simulation were obtained by setting a number of analysis steps. A clear yield point position can be obtained through the stress analysis of each analysis step, and the defects of distinguishing the yield point were improved. Table 3 shows that the yield rotation angles of FEA were smaller than the experimental values, thereby indicating that the simplified numerical model entered the state of yield in advance.

(4) The ductility coefficients of the A group specimens were greater than four, which satisfied the ductility requirement of the joints in the general frame. The reasonable ductile failure mode was obtained by the reasonable material property and boundary condition, which can improve the deficiency of brittle failure in the test, this was also the reason for the approximately $18 \%$ higher ultimate rotation angles of group B specimen than that of the experiment. However, the displacement ductility coefficients of group B specimens were still less than four, and the ductility was poor.

(5) The comparison of the hysteresis and the skeleton curves shows that the numerical simulation had an accuracy problem. However, using ABAQUS to model the entire nonlinear process of the outer shell joint under the low-cycle reciprocating load was reasonable. Therefore, the damage mechanism and influence parameters of the joints can be studied based on the numerical results. 
Table 3. Comparison of test and finite element results

\begin{tabular}{|c|c|c|c|c|c|c|}
\hline $\begin{array}{l}\text { Specimen } \\
\text { number }\end{array}$ & & $\begin{array}{l}\text { Yield } \\
\text { Moment } \\
M_{y}(\mathrm{kN} \cdot \mathrm{m})\end{array}$ & $\begin{array}{l}\text { Ultimate moment } \\
M_{u}(\mathrm{kN} \cdot \mathrm{m})\end{array}$ & $\begin{array}{l}\text { Yield } \\
\text { angle }\end{array}$ & $\begin{array}{ll}\text { Ultimate } & \text { rotation } \\
\text { angle } & \\
\theta_{u}(\mathrm{rad}) & \end{array}$ & $\begin{array}{l}\text { Ductile coefficient } \\
\mu\end{array}$ \\
\hline \multirow{2}{*}{ STj-A } & FEA & 106.63 & 167.45 & 0.027 & 0.115 & 4.26 \\
\hline & Test & 97.64 & 154.35 & 0.027 & 0.131 & 4.85 \\
\hline \multirow{2}{*}{ CFSTj-A } & FEA & 101.51 & 154.37 & 0.021 & 0.089 & 4.24 \\
\hline & Test & 102.52 & 164.28 & 0.026 & 0.128 & 4.92 \\
\hline \multirow{2}{*}{ STj-B } & FEA & 172.95 & 250.07 & 0.022 & 0.078 & 3.55 \\
\hline & Test & 175.21 & 241.34 & 0.031 & 0.066 & 2.13 \\
\hline \multirow{2}{*}{ CFSTj-B } & FEA & 174.35 & 251.23 & 0.021 & 0.073 & 3.48 \\
\hline & Test & 178.50 & 230.18 & 0.029 & 0.062 & 2.14 \\
\hline
\end{tabular}

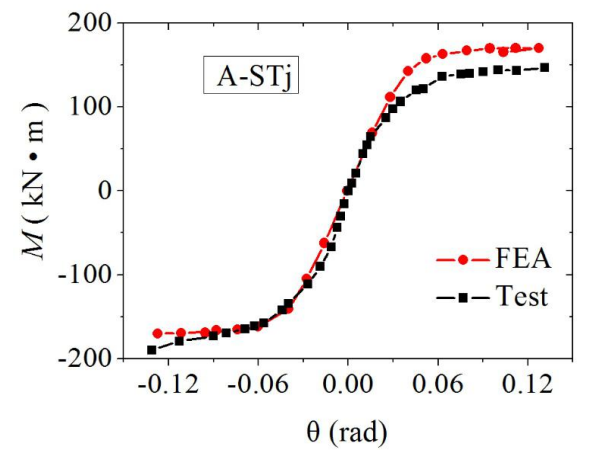

(a)

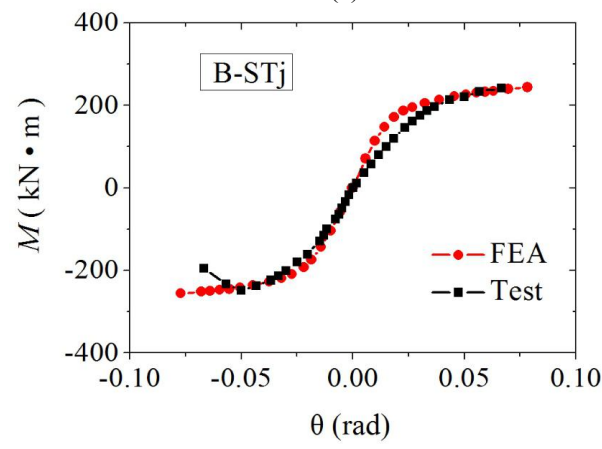

(c)

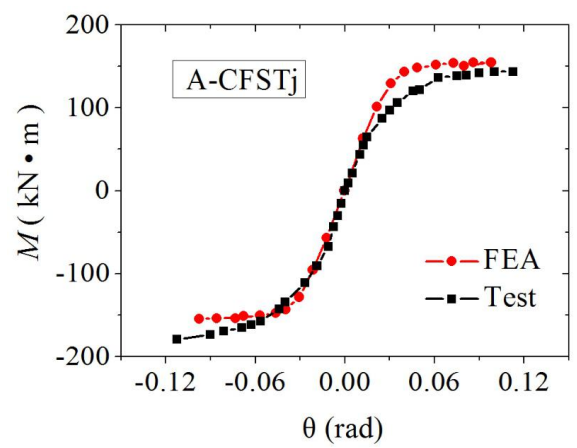

(b)

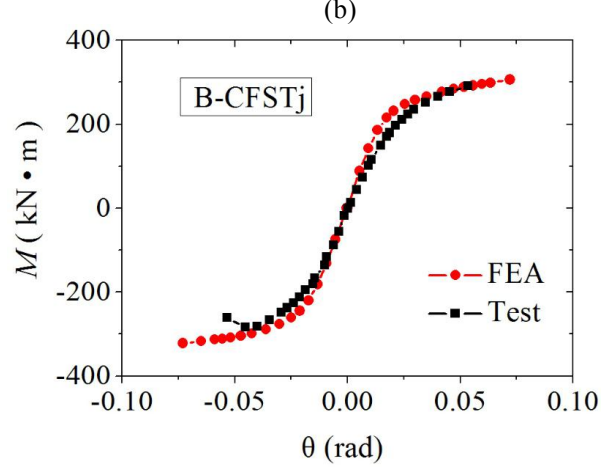

(d)

Fig. 17. Comparison of skeleton curves. (a) STj-A. (b) CFSTj-A. (c) STj-B. (d) CFSTj-B

\subsection{Parameter analysis}

The joint core region was the intersecting part of the beam and column, and the force characteristics were complicated. Hence, studying the influences of the joint region parameters on the seismic performance was necessary. The shear force and bending moment acting on the beam end were transferred to the column wall by T-type steel effectively, and the column walls were strengthened by the outer shells, which effectively improved the performance of the joint. Hence, on the basis of the STj-A specimen, the main indexes, namely, the thickness of the outer shell and the T-steel web, were discussed.

\subsubsection{Thickness of outer shell}

The thickness of the outer shell was one of the main factors that affected the performance of the joint. The increase in the thickness of the outer shell can improve the yield bearing capacity, ultimate bearing capacity, and initial stiffness of the joint. Thicknesses of $4,8,16$, and $24 \mathrm{~mm}$ of the outer shell were compared and analyzed without changing other parameters to discuss the reasonable value of outer shell thickness. Results are shown in Fig. 18 and Table 4.

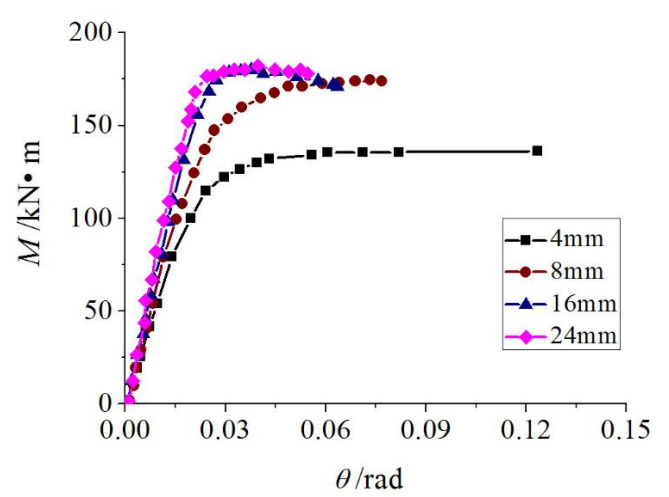

Fig. 18. Effect of outer shell thickness on moment-rotation curve

It is shown that the yield and ultimate load increased with the increase in the outer shell thickness. When the thickness of the outer shell was increased from $4 \mathrm{~mm}$ to 8 $\mathrm{mm}$, the yield bearing capacity and the ultimate bearing capacity improved by $8.5 \%$ and $28.1 \%$, respectively, however, the yield rotation angle decreased slightly. With an increase from $8 \mathrm{~mm}$ to $16 \mathrm{~mm}$, the ultimate bearing capacity was enhanced by only $2.1 \%$. Continued to increase the thickness of the outer shell, the increase in the bearing capacity was not large, and the deformation was further reduced, thereby indicating that when the thickness was 
more than $8 \mathrm{~mm}$, the influence on the performance of the joint was limited. Therefore, the thickness of the outer shell was recommended to be approximately $8 \mathrm{~mm}$.

Table 4. Effect of outer shell thickness on bearing capacity

\begin{tabular}{l|l|l|l}
\hline $\begin{array}{l}\text { Thickness } \\
(\mathbf{m m})\end{array}$ & $\begin{array}{l}\text { Yield moment } \\
M_{y}(\mathrm{kN} \cdot \mathrm{m})\end{array}$ & $\begin{array}{l}\text { Yield rotation } \\
\text { angle } \\
\theta_{y}(\mathrm{rad})\end{array}$ & $\begin{array}{l}\text { Ultimate } \\
\text { moment } \\
M_{u}(\mathrm{kN} \cdot \mathrm{m})\end{array}$ \\
\hline 4 & 114.74 & 0.024 & 136.29 \\
8 & 124.47 & 0.020 & 174.54 \\
16 & 131.42 & 0.017 & 178.26 \\
24 & 148.27 & 0.018 & 180.43 \\
\hline
\end{tabular}

\subsubsection{Thickness of T-steel web}

The web-root section of T-type steel was subjected to the action of tension and shear, and the stress concentration was easily formed. Without changing other parameters, on the basis of the influences of the thickness of the T-steel web on the mechanical properties of the joint, as well as considering whether the T-type steel had a stiffener rib, thicknesses of 11 and $15 \mathrm{~mm}$ of the T-steel web were selected. Four types of outer shell joints were monotonically loaded, and the effects of the T-steel web thickness on the performance of the joint are shown in Fig. 19 and Table 5.

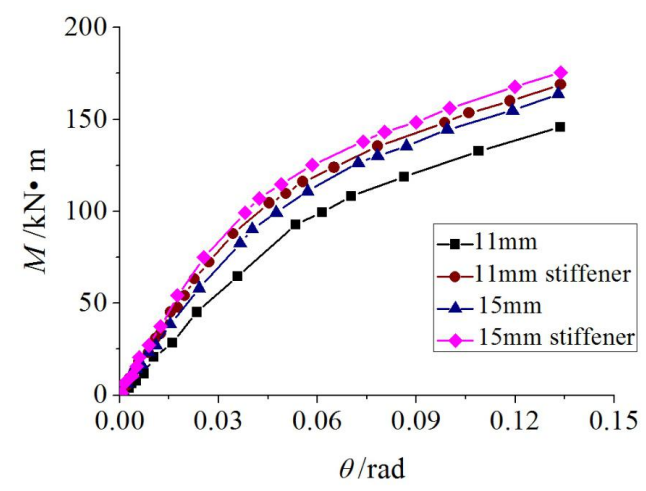

Fig. 19. Effect of T-steel web thickness on moment-rotation curve

Table 5. Effect of T-steel web thickness on bearing capacity

\begin{tabular}{l|l|l|l}
\hline $\begin{array}{l}\text { Thickness } \\
(\mathbf{m m})\end{array}$ & $\begin{array}{l}\text { Yield moment } \\
M_{y}(\mathrm{kN} \cdot \mathrm{m})\end{array}$ & $\begin{array}{l}\text { Yield rotation } \\
\text { angle } \\
\theta_{y}(\mathrm{rad})\end{array}$ & $\begin{array}{l}\text { Ultimate } \\
\text { moment } \\
M_{u}(\mathrm{kN} \cdot \mathrm{m})\end{array}$ \\
\hline 11 & 88.64 & 0.048 & 145.81 \\
11 (stiffener) & 104.50 & 0.045 & 169.03 \\
15 & 95.32 & 0.043 & 163.87 \\
15 (stiffener) & 107.09 & 0.042 & 175.48 \\
\hline
\end{tabular}

It is shown that the ultimate bearing capacity of the 15 mm thick T-steel web was $12.4 \%$ higher than that of the 11 $\mathrm{mm}$ thick T-steel web in the absence of stiffening ribs. Considering the stiffened ribs, the ultimate bearing capacity increased by only $3.8 \%$ when the thickness of the T-steel web increased from $11 \mathrm{~mm}$ to $15 \mathrm{~mm}$. When the thickness was $11 \mathrm{~mm}$, the bearing capacity of the stiffened joint was $15.9 \%$ higher than that of the non-stiffening joint, and it increased by $7.1 \%$ when the thickness was $15 \mathrm{~mm}$. In summary, increasing the thickness of the T-steel web can increase the bearing capacity of the joint, however, setting the stiffener was more effective.

\section{Conclusions}

This study proposed a new type of full-bolted outer shell joint of square steel tubular column and H-steel beam connected by T-type steel to eliminate the shortcomings of the beam-column welding joints of traditional steel frames and to improve the connection of existing joints. Subsequently, the low-cycle reciprocating load test of four different parameters of the outer shell joints was conducted, and the failure modes, hysteresis curves, skeleton curves, and stiffness degradation were studied. In addition, the finite element method was used to evaluate the effects of the main parameters on the seismic performance of joints. The following conclusions were drawn:

(1) Two kinds of failure modes of the outer shell joints exist: buckling failure of beam flange and fracture failure of T-steel web root. Notably, the cross-sectional dimensions of the joint have a considerable influence on the failure mode of the specimen. Increasing the size of the joint can effectively improve the bending capacity and the initial stiffness. Similarly, the initial stiffness can also be improved to a certain extent by filling concrete in the steel tube column.

(2) The hysteresis curves of the outer shell joint are full with a slight pinching. Compared with the CFST joints, the hysteresis loop area of the steel tubular joints is plumper, the energy dissipation ability of the smaller joints is stronger. Owing to the cumulative damage of the joints in the loading process, the skeleton curves are not completely symmetrical, and different degrees of stiffness degradation are observed.

(3) The strain values of the outer shell and the adjacent steel tube column wall are analyzed. The synergistic deformation performance of the two components is different in the elastic and plastic stage while the change trend is consistent, thereby showing that the outer shell can strengthen the column wall effectively.

(4) The FEA models are verified in terms of the moment-rotation skeleton curves. Parametric analysis shows that when the thickness of the outer shell exceeds a fixed value, the increase in the bearing capacity of the outer shell joint is limited. In addition, the setting stiffener rib more effectively improves the bearing capacity of joints than increasing the thickness of the T-steel web.

In this study, the full-bolted outer shell joints of square steel tubular column and H-steel beam connected by $\mathrm{T}$ shaped steel have the advantages of good mechanical performance, efficient and professional construction, thereby providing technical supports for the application. However, the number of specimens is small. Hence, the mechanical properties of the study are relatively limited, and other parameters require further study.

\section{Acknowledgements}

This work was supported by the National Science and Technology Support Program of China (No. 2013BAK13B01).

This is an Open Access article distributed under the terms of the Creative Commons Attribution Licence

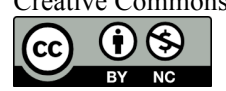




\section{References}

1. Shi, Y. L., Shi, X. F., Wang, W. D., Wang, J. X., Li, H. W., "Progressive collapse mechanism analysis of H-beam to concretefilled steel tubular column with steel inner-diaphragm joints". Journal of Vibration and Shock, 35(19), 2016, pp.148-155.

2. Li, L., Wang, W., Chen, Y. Y., Teh, L. H., "Column-wall failure mode of steel moment connection with inner diaphragm and catenary mechanism". Engineering Structures, 131, January 15, 2017, pp.553-563.

3. Li, Z. L., Zhang, C., Xue, J., Zhou, X. J., "Experimental studies on all-bolts and diaphragm-through joint's aseismic behavior of concrete-filled steel tubular structure". Engineering Mechanics, 31(11), 2014, pp.116-123.

4. Zhu, L., Yang, K., Bai, Y., Sun, H. L., Wang, M., "Capacity of steel CHS X-joints strengthened with external stiffening rings in compression”. Thin-Walled Structures, 115, June, 2017, pp. 110118.

5. Wang, J. F., Chen, L. P., "Experimental investigation of extended end plate joints to concrete-filled steel tubular columns". Journal of Constructional Steel Research, 79, December, 2012, pp.56-70.

6. Chen, Y., Wu, Y., "Behaviour of square hollow section brace-Hshaped steel chord T-joints under axial compression". Thin-Walled Structures, 89, April, 2015, pp.192-204.

7. Dessouki, A. K., Yousef, A. H., Fawzy, M. M., "Investigation of inplane moment connections of I-beams to square concrete-filled steel tube columns under gravity loads". Housing and Building National Research Center Journal, 11(1), 2015, pp.43-56.

8. Deylami, A., Toloukian, A. R., "Effect of geometry of vertical rib plate on cyclic behavior of steel beam to built-up box column moment connection". Procedia Engineering, 14, 2011, pp.30103018.

9. Liu, Y., Málaga-Chuquitaype, C., Elghazouli, A.Y., "Response and component characterisation of semi-rigid connections to tubular columns under axial loads". Engineering Structures, 41, August, 2012, pp.510-532.
10. Yang, B., Tan, K. H., "Experimental tests of different types of bolted steel beam-column joints under a central-column-removal scenario". Engineering Structures, 54, September, 2013, pp.112130.

11. Wang, Z. Y., Wang, Q.Y., Xue, H., Liu, X.K., "Low cycle fatigue response of bolted T-stub connections to HSS columnsExperimental study". Journal of Constructional Steel Research, 119, March, 2016, pp.216-232.

12. Rong, B., Chen, Z., Zhang, R., Fafitis, A., Yang, N., "Experimental and analytical investigation of the behavior of diaphragm-through joints of concrete-filled tubular columns". Journal of Mechanics of Materials and Structures, 7(10), 2012, pp.909-929.

13. Rong, B., Liu, R., Zhang R. Y., Chen Z. H., Apostolos, F., "Flexural bearing capacity of diaphragm-through joints of concrete-filled square steel tubular columns". Steel and Composite Structures, 20(3), 2016, pp.487-500.

14. Han, Q. H., Liu, M. J., Lu, Y., Xu, Y., Xu, J., "Experimental research on static behavior of cast steel joints for $\mathrm{H}$-shaped beam and square tube column". Journal of Building Structures, 36(9), 2015, pp.101-109.

15. Yang, J., Sheehan, T., Dai, X. H., Lam, D., "Structural behaviour of beam to concrete-filled elliptical steel tubular column connections". Structures, 9, February, 2017, pp.41-52.

16. Augusto, H., Castro, J. M., Rebelo, C., Silva, L. S., "Characterization of the cyclic behavior of the web components in end-plate beam-to-column joints". Procedia Engineering, 160, 2016, pp.101-108.

17. Xiao, A. L., He, Y. B., Guo, J., "Stress-strain relation of core concrete of aixally-loaded steel tubular columns filled with steelreinforced concrete". Journal of Central South University (Science and Technology), 41(1), 2010, pp.341-346. 